JOALL (JOURNAL OF APPLIEI) UNGUIS'TICS ANI) II'TERA'TURE)

Vol. 4 No.2, 2019

ISSN (print): 2502-7816; ISSN (online): 2503-524X

Available online at https:/ / ejournal.unib.ac.id/index.php/joall/index doi: http://dx.doi.org/10.33369/joall.v4i2.7623

\title{
A CORPUS-BASED ANALYSIS OF VERBS IN NEWS SECTION OF THE JAKARTA POST: HOW FREQUENCY IS RELATED TO TEXT CHARACTERISTICS
}

\author{
Ikmi Nur Oktavianti'; Novi Retno Ardianti² \\ Universitas Ahmad Dahlan ${ }^{1,2}$ \\ Corresponding email: ikmi.oktavianti@pbi.uad.ac.id
}

\begin{abstract}
Verb is one of the most important word classes in linguistic construction due to its prominent role and dynamic nature. Interestingly, the use of verbs in different linguistic contexts might be various because the context can limit or allow certain verbs to occur more frequently than other verbs. It is compelling to study further the use of verbs in a particular linguistic context. This paper thus aims at examining the use of verbs in news section in The Jakarta Post to figure out the frequency of verbs and how it relates to the characteristics of news text. This study compiled The Jakarta Post corpus comprising news articles belong to the category of hard news from October to December 2018 with total size of 21.682 words. The verb types used in this study refer to those compiled by Scheibmann (combining Halliday's verb taxonomy and Dixon's verb types). Based on the analysis, it is obvious that verbal type is the most frequent verb type, followed by material and existential. As for the least frequent ones, there are corporeal and perception/relational types. It is plausible that verbal type occupies the most frequent position because the nature of news text is to deliver information and thus it needs to use verbal verbs quite often. Likewise, material verb is frequent because it states concrete action and existential verb denotes existence; both are vital in constructing news text. Meanwhile, corporeal and perception/relational types are least frequent because corporeal deals with bodily gestures actions and perception/relational shows subjectivity. Both verb types are rather insignificant concepts in news writing. Based on the results of analysis, it is obvious that there is a firm relation between frequency of verbs used in news text and the characteristics of the text: linguistic units that are not in accordance with the function of the text are not really needed and thus infrequently used.
\end{abstract}

Keywords: corpus, news, frequency, text characteristics 


\section{INTRODUCTION}

Verb is one of the most prominent linguistic units in all languages, along with noun and adjective in lexical category group. As stated by Chafe (1970), verb holds crucial role as it determines the arguments of the clauses, including the types and the number of arguments. In addition, verbs - in some languages-are the linguistic units where tenses and other grammatical categories are attached to (Comrie, 2000). In English, if there is no tense, the clause is ungrammatical, and by which it emphasizes the importance of verb. Compared to noun, verb is more dynamic because naturally it states actions, events, states, while noun refers to static entities (Clackson, 2007). However, statistically, noun is more frequent than verb in a way that noun labels objects and concepts of the world. Thus, in terms of number, nouns are more significantly important, but in terms of function, verbs determine the noun possible to occur in the clause/sentence. As an empirical evidence, the observation of verb frequencies in Corpus of Contemporary American English (COCA) (Davies, 2008) and British National Corpus (BNC) (Davies, 2004) proves that verbs occupy the second most frequent word class following noun or $10 \%$ of the total size of the corpora, as is mentioned in table 1.

Table 1. Absolute frequency of lexical categories in COCA and BNC

\begin{tabular}{lll} 
Word Class & COCA & BNC \\
\hline Nouns & $114.644 .292(20 \%)$ & $19.451 .274(20 \%)$ \\
\hline Verbs & $61.188 .902(10 \%)$ & $9.827 .956(10 \%)$ \\
\hline Adjectives & $38.314 .634(7 \%)$ & $6.826 .047(7 \%)$ \\
\hline
\end{tabular}

Talking about the use of verbs, it might be influenced by the context where the verbs are used. It is assumed that the use of linguistic units might differ in different linguistic context, e.g., different text categories, different medium, different dialects (Bybee \& Hopper, 2001; Oktavianti, 2016, 2019). Scheibmann in Bybee and Hopper (2001) finds out that the use of certain verbs (e.g., feel, believe) tend to follow first person singular $(I)$ subject. Oktavianti (2019) investigates that modal verbs be going to is more frequent in spoken language than in written language. It shows that the medium of language use determines which linguistic unit is more appropriate to be used. It means that certain medium or certain linguistic context has its own characteristics that enable certain linguistic unit to occur more frequently than others. It is intriguing to further study the use of verbs in a particular linguistic context of which this study focuses on written medium of language use represented by newspaper.

As one of written media of language use, newspaper has gained its popularity compared with fiction and academic from the same written medium. Considering that each text category has its own characteristics, this study focuses on studying newspaper or news text, especially on how the 
verbs are used in the text. It is crucial to study language use in news text since the language used in newspapers is the closest to language used in daily life (Bell, 1991; Conboy, 2010). In fiction, the language is manipulatively used (Leech \& Short, 2007) and academic texts require standard form of language use (Biber \& Gray, 2016). Thus, to depict actual language use, studying language in media, including newspaper, is the best option to enable comprehensive analysis. Talking about news texts, based on the nature, they can be classified into hard news and soft news (Bell, 1991). To limit the focus, this study analyses hard news in news section of The Jakarta Post. The selection of the newspaper is not a difficult task since The Jakarta Post is the most well-established and also the oldest English newspaper in Indonesia. Hence it is easier for the access and the compilation of the corpus and it provides rich and various data because of the enormous contents of the newspaper.

This study uses corpus linguistics and text analysis as the framework of analysis. Using corpus enables more empirical approach and provides richer data to the analysis. Besides, using corpus can lead to faster and more accurate analysis of frequency of use in which frequency is the key analysis of corpus linguistics (Biber \& Quirk, 2012). Besides, by using corpus and focusing the analysis on frequency of linguistic units, it is plausible to find what is actually important. As stated by Baker (2010: 125), frequency indicates markedness; it indicates that something that frequently occurs is an important concept. Related to linguistic analysis, linguistic unit that frequently occurs in a particular text marks the unit as a typical feature of the text.

In analyzing the use of a linguistic unit, it is necessary to consider the medium of the language use and the characteristics of the texts. Halliday (1990: 93) argues that spoken language differs from written language due to its own distinct characteristics. Spoken language uses prosodic and paralinguistic features to assist message delivery, while written language does not have such tools. Moreover, written language allows revision, yet spoken language is more spontaneous (Biber \& Conrad, 2009). Talking about written language, it has various text categories, e.g., news, fiction, academic, etc. News texts and academic texts have similar purpose that is to deliver information. They differ, however, in terms of the depth of the information delivery and types of information being delivered. Academic texts discuss the information profoundly and develop arguments scientifically (Biber \& Conrad, 2009). Meanwhile, fiction is easily distinguished from two other text categories since it manipulates language use beautifully to build imaginary story and characters (Leech \& Short, 2007). Based on the differences, it is believed that different text categories might enable different linguistic units 
to occur more frequently; or else they might limit the use of certain linguistic units/features so they occur less frequently.

This study focuses on the analysis of newspaper as one of mass media to represent everyday language. The purpose of media is to deliver information, to give entertainment and to educate (Thomas et al., 2004). Thus the language use in media should be as close as possible to their viewers or readers. In newspaper context, the language used in the newspaper is the language used in the society (Bell, 1991: 3). The language used in newspaper is pretty much close and similar to what people use in everyday life. Besides, it emphasizes on the updated information delivered daily so the language used needs to be as effective and efficient as possible. In line with Bell, because it is read on daily basis by people in the society, language of newspaper is adapting to the existence of contemporary communication flow (Conboy, 2010: 3). Regarding the object of this study, there is some tendencies related to the use of verbs in news text. Verbs in news text tend to be in the form of present tense, and active voice is chosen more intensely over passive voice to cover some purposes (Bednarek \& Caple, 2012; Biber \& Conrad, 2009; Biber \& Quirk, 2012).

Previous studies on language use in newspaper focused on the linguistic features that are typical to the text category (Bednarek \& Caple, 2012; Biber \& Quirk, 2012). Moreover, language in newspaper has been analyzed using corpus-based analysis (Deng \& Li, 2017; Moon, 2016; Wang, 2015). In relation to verbs, some corpus studies have been done to analyze verbs, such as how verbs are acquired (Nordlund, 2008), the use of verbs in legal context (Denyer, 2003), the use of reporting verbs by native and nonnative speakers (Yilmaz \& Ertürk, 2017), and also critical review on phrasal verbs (Zarifi \& Mukundan, 2013). Nonetheless, specific discussions on verbs used in newspaper are mainly limited to types of tenses, voice choice, and transitivity (Bednarek \& Caple, 2012; Biber \& Quirk, 2012; Conrad \& Biber, 2001). The use of verbs in news section, especially in The Jakarta Post, using corpus-based analysis has not been widely discussed. Therefore this corpusbased study is expected to describe verb frequency and how it is related to text characteristics. In addition, this study can give empirical evidence on the importance of frequency as a concept and key analysis in linguistics, especially text analysis.

\section{METHODS}

This study employs corpus-based approach so it compiled data from news section of The Jakarta Post from October-December 2018 comprising 21.682 words. The compiled corpus was then analyzed by identifying the verbs used as well as the absolute frequencies of the verbs. The first investigation was done using Lancsbox corpus tool (Brezina, Timperley, \& McEnery, 2018). 
In Lancsbox, Words feature is used to count the frequency validly. Using Words in Lancsbox, it is easier to identify all verbs used in the corpus by sorting the type into lemma and filtering the result box by inserting [ $\left.{ }^{*} \mathrm{v}\right]$ to limit the results for verb word class only. The corpus tool also arranges the frequency based on the order from the highest to the smallest ones so it is no need to manually arrange the frequency. The next investigation of frequency was carried out by classifying the verbs into verb types as compiled by Scheibmann (in Bybee and Hopper, 2001) in which she compiled verb taxonomy of Halliday (Halliday \& Matthiessen, 2004) and verb types of Dixon (Dixon, 2005). The verb types are as follows.

Table 2. Verb types compiled by Scheibmann (in Bybee and Hopper, 2001)

\begin{tabular}{ll}
\hline Verb Type & Description \\
\hline Cognition & cognitive activity \\
\hline Corporeal & bodily gesture, bodily interaction \\
\hline Existential & exist, happen \\
\hline Feeling & emotion, wanting \\
\hline Material & concrete and abstract doings and happenings \\
\hline Perception & perception, attention \\
\hline Perception/Relational & perception (subject not senser) \\
\hline Possessive/Relational & possession \\
\hline Relational & process of being \\
\hline Verbal & saying, symbolic exchange of meaning \\
\hline
\end{tabular}

There is, however, the tendency of ambiguity for some words, e.g. look that can be classified into either perception or perception/relational. To solve this problem, this study used Lancsbox concordance feature, KWIC, to distinguish which look belongs to which type. As for the second problem proposed in this study, quantitative procedure is not relevant. To relate frequency and characteristics of text, this study modified the concept of thick description proposed by Geertz (Stake, 2010) to interpret the relationship as shown by the data, findings, and the theory. In interpreting, this study profoundly relates the available findings with the relevant theory, i.e. the theory of news text characteristics.

\section{FINDINGS}

This section discusses frequency of verb types and what are the most and the least frequent verb types in the corpus. To begin with, there is the discussion on verb type frequencies investigated based on Scheibmann's compilation of verb types. Below is the list of the frequency of the verbs found in the corpus of news section in The Jakarta Post.

Table 3. Frequency of verb types

\begin{tabular}{ll}
\hline Verb Type & Frequency \\
\hline Verbal & $327(43.4 \%)$ \\
\hline Material & $146(19.4 \%)$ \\
\hline Existential & $121(16 \%)$ \\
\hline
\end{tabular}




\begin{tabular}{ll}
\hline Verb Type & Frequency \\
\hline Perception & $45(6 \%)$ \\
\hline Feeling & $39(5.2 \%)$ \\
\hline Possessive/Relational & $28(3.73 \%)$ \\
\hline Cognition & $26(3.47 \%)$ \\
\hline Relational & $17(2.26 \%)$ \\
\hline Corporeal & $3(0.4 \%)$ \\
\hline Perception/Relational & $1(0.14 \%)$ \\
\hline
\end{tabular}

Table 3 clearly shows that that verbal type is the most frequent verb type found in the corpus of The Jakarta Post news section. This verb type dominates the whole corpus by occurring $43.4 \%$ of all verbs found. Table 3 also presents the other most frequent verb types, namely material and existential types. As for the less frequent verb types, there are perception (6\%), feeling $(5.2 \%)$, possessive/relational (3.73\%), cognition $(3.47 \%)$, and relational $(2.26 \%)$ respectively. Meanwhile, the other two types, corporeal and perception/relational belong to the least frequent verb types found in news section in The Jakarta Post. The detailed description of verb type frequencies is listed in table 4 below.

Table 4. Detailed display of verb frequencies

\begin{tabular}{|c|c|c|c|c|c|}
\hline Rank & Verb Type & Verb & $\begin{array}{c}\text { Token } \\
\text { Frequency }\end{array}$ & $\begin{array}{c}\text { Total } \\
\text { Frequency }\end{array}$ & $\begin{array}{c}\text { Percentage } \\
(\%)\end{array}$ \\
\hline \multirow[t]{3}{*}{1} & \multirow[t]{3}{*}{ Verbal } & say & 273 & \multirow[t]{3}{*}{327} & \multirow{3}{*}{43.4} \\
\hline & & tell & 38 & & \\
\hline & & ask & 14 & & \\
\hline \multirow[t]{7}{*}{2} & \multirow[t]{7}{*}{ Material } & take & 39 & \multirow[t]{7}{*}{146} & \multirow[t]{7}{*}{19.4} \\
\hline & & do & 36 & & \\
\hline & & go & 22 & & \\
\hline & & come & 22 & & \\
\hline & & use & 14 & & \\
\hline & & work & 8 & & \\
\hline & & play & 5 & & \\
\hline \multirow[t]{2}{*}{3} & \multirow[t]{2}{*}{ Existential } & have & 109 & \multirow[t]{2}{*}{121} & \multirow[t]{2}{*}{16} \\
\hline & & happen & 12 & & \\
\hline \multirow[t]{3}{*}{4} & \multirow[t]{3}{*}{ Perception } & see & 20 & \multirow[t]{3}{*}{45} & \multirow[t]{3}{*}{6} \\
\hline & & find & 20 & & \\
\hline & & hear & 5 & & \\
\hline \multirow[t]{3}{*}{5} & \multirow[t]{3}{*}{ Feeling } & want & 17 & \multirow[t]{3}{*}{39} & \multirow[t]{3}{*}{5.2} \\
\hline & & need & 15 & & \\
\hline & & feel & 7 & & \\
\hline 6 & Possessive/Relational & have & 28 & 28 & 3.73 \\
\hline \multirow[t]{3}{*}{7} & \multirow[t]{3}{*}{ Cognition } & know & 14 & \multirow[t]{3}{*}{26} & \multirow[t]{3}{*}{3.47} \\
\hline & & describe & 7 & & \\
\hline & & think & 5 & & \\
\hline \multirow[t]{2}{*}{8} & \multirow[t]{2}{*}{ Relational } & become & 10 & \multirow[t]{2}{*}{17} & \multirow[t]{2}{*}{2.26} \\
\hline & & get & 7 & & \\
\hline
\end{tabular}




\begin{tabular}{llllll}
\hline Rank & \multicolumn{1}{c}{ Verb Type } & Verb & $\begin{array}{c}\text { Token } \\
\text { Frequency }\end{array}$ & $\begin{array}{c}\text { Total } \\
\text { Frequency }\end{array}$ & $\begin{array}{c}\text { Percentage } \\
(\%)\end{array}$ \\
\hline 9 & Corporeal & live & 3 & 3 & 0.4 \\
\hline 10 & Perception/Relational & look & 1 & 1 & 0.14 \\
\hline
\end{tabular}

Table 4 shows that for the most frequent verb type, verbal, the most frequent verb is say (including the inflected forms, says, saying, said). In the subsequent order, there are tell and ask that also belong to verbal type, although tell (237 occurrences) is more frequent than ask (14 occurrences). For material type, there are several verbs included, such as take, do, go, come, use, work, and play (including the inflected forms), while existential type covers have and happen. Those are the three most frequent verb types found in the corpus. According to the verbs, however, verb say and have occupy the highest ranks in the corpus.

As for the less frequent verb types, perception, feeling, possessive/relational, cognition, and relational, they also comprise several verbs as is displayed in table 4 . The most interesting part to notice is the least frequent verb types, i.e. corporeal and perception/relational. In corporeal verb type, it only comprises of one verb, live ( 3 occurrences) and so do perception/relational type. It consists of one verb, look, in which the subject is not the senser. It is evident that table 4 shows empirical evidence that there are some verbs used more frequently than other verbs; in this case, it is in news text category.

\section{DISCUSSION}

In this section, the discussion focuses on how frequency of verbs is related to the characteristics of news text. As a text category, news obviously differs from other text categories. This is due to the main role of news section, e.g., hard news, is to deliver information or factual events happened in the society. Hard news contains report of accidents, conflicts, crimes, announcements, discoveries and other events that has occurred since the previous issue of their paper (Bell, 1991: 14). To achieve this function, news texts should use certain linguistic features to assist the message delivery. Bednarek \& Caple (2012) states that the use of present tense verbs is slightly more often than past tense verbs. This is in accordance with the relevant information delivered in news, such as ongoing relevant process (e.g., is comparing), laws (e.g., allows), and timeless truth (e.g., The Earth revolves around the sun). Bednarek \& Caple (2012) also states that the use of past tense, although it is less frequent than present tense, is necessary to provide information (i.e., temporal information) of the events that happened.

Related to verb types compiled by Scheibmann, verbal type holds important role since it is related to message delivery. Verb like say means 
'utter words so as to convey information, an opinion, a feeling or intention, or an instruction' and belongs to reporting verb (Oxford Dictionary of English). It means that this verb is one of the main lexical elements in news writing as it corresponds to what news text is about. Likewise, other verbal verbs (e.g., tell and ask) can be found in the corpus and especially verb tell has pretty high frequency. The next most frequent verbs are material verbs that occupy $19.4 \%$ of the corpus size. Verbs belong to material type express concrete actions (Scheibmann in Bybee \& Hopper, 2001) in which these are needed in the description of the event reporting. To complete the writing of the events (e.g., the description of conflicts, crimes, accidents, etc.), the journalists need to elaborate the details of the events, including the actions happened; hence this type is also frequent in the corpus. Without the description of the actions concretely, the reporting of the events will not be satisfactory. Following verbal and material, existential verb type holds the third most frequent type ( $16 \%$ of the total verb frequencies in the corpus) since it is crucial to state the existence (e.g., using happen) in describing events. This sort of verb assists the portrayal of time and place of the events being described by the news text. As defined by Oxford Dictionary of English, existence means 'the fact or state of living or having objective reality', verbs expressing existence thus are important in news writing to report the event objectively by stating the fact or state of the events.

Verbs belong to perception, feeling, possessive/relational, cognition, and relational occur rarely in the corpus (although not the least ones) due to the nature and function of news text. According to their nature, perception and feeling tend to be more subjective and personal; those are avoided in writing news, especially hard news. Meanwhile, cognition verbs show someone's assumption or understanding, something that is likely important in the proper context, but not quite prominent in writing hard news. The use of them hence is not frequent enough compared to verbal, material, and existential verbs. Still discussing the less frequent ones, possessive/relation also belongs to this classification because it occurs $3.73 \%$ of all verbs found in the corpus. It is the case since possessive/relational denotes possession and it tends to be more personal so it is unsurprising if the use of possessive/relational verb is negligible. The last verb type that is said to be less frequent is relational type. As mentioned by Scheibmann (in Bybee \& Hopper, 2001), relational type states process of being and this kind of verb nature is quite unimportant in constructing news so it occupies the category of less frequent one.

The relationship of text characteristics and the least frequent verbs can also be analyzed. As is described previously, there are corporeal and perception/relational having the smallest number of frequencies among all other verb types in the corpus. This is probably because of the irrelevance of 
the nature of the verbs and the function of news text. Corporeal verbs denote bodily gestures or bodily states that are too specific to some extent so that this type is rather unnecessary in writing news. Besides corporeal type, perception is of little importance in writing news - as proven by the empirical evidence from the corpus. This is likely related to the subjectivity embodied by the verb. As defined by Oxford Dictionary of English, perception is related to sense and/or interpretation so it tends to be subjective. News text, however, attempts to be as objective as possible, thus it focuses on the description of the events objectively. Therefore linguistic features that are not in accordance with the task of news text to report factual events are not pretty much needed, even though they are still used infrequently.

To summarize the relationship between frequency of verb types and characteristics of news text, below is table 5 presenting the highlighted points in regard to the most frequent verb types.

Table 5. Summary of relationship between frequency and text characteristics (most frequent types)

\begin{tabular}{lll}
\hline Most frequent verb types & \multicolumn{1}{c}{$\begin{array}{c}\text { The nature of the } \\
\text { verb types }\end{array}$} & $\begin{array}{l}\text { Why the verb types are } \\
\text { needed in news text }\end{array}$ \\
\hline verbal & to deliver message & $\begin{array}{l}\text { to assist the portrayal of } \\
\text { information or factual } \\
\text { events } \\
\text { to describe the events } \\
\text { concretely } \\
\text { to state the existence of the } \\
\text { existential }\end{array}$ \\
to state concrete actions \\
to state existence
\end{tabular}$\quad \begin{aligned} & \text { place) } \\
& \end{aligned}$

As for the least frequent verb types, corporeal and perception/relational, table 6 below shows the summary of the relationship.

Table 6. Summary of relationship between frequency and text characteristics (least frequent types)

\begin{tabular}{|c|c|c|}
\hline Least frequent verb types & $\begin{array}{l}\text { The nature of the } \\
\text { verb types }\end{array}$ & $\begin{array}{l}\text { Why the verb types are least } \\
\text { needed in news text }\end{array}$ \\
\hline corporeal & $\begin{array}{l}\text { to express bodily gestures or } \\
\text { bodily state }\end{array}$ & $\begin{array}{l}\text { it is not quite necessary to } \\
\text { state bodily gestures in } \\
\text { writing news text }\end{array}$ \\
\hline perception/relational & $\begin{array}{l}\text { to express perception of } \\
\text { thing }\end{array}$ & $\begin{array}{l}\text { news text consists of factual } \\
\text { events description and } \\
\text { attempts to be as objective as } \\
\text { possible so the use of } \\
\text { perception/relational verb is } \\
\text { insignificant }\end{array}$ \\
\hline
\end{tabular}

Less frequent verb types are basically less important in assisting the delivery of report, but they are occasionally needed to add some details in news writing, so the use is obviously infrequent. In short, the verb types found to be the most frequent types are those needed the most in news 
writing. The three most frequent types, verbal, material, and existential are prominent in writing news and are related to news text characteristics because they can be used to refer to the events described in the news text, especially related to the reporting, the concrete actions, and the existence of the events in regard to time and place. As described by Leitner (1986: 189), linguistic features belong to the main components of news are those that can be used to refer to the details of news writing, such as actors, times, places, and relate to at least some of basic facts on reporting. Meanwhile, linguistic features (including verbs) that are irrelevant with the function of news text and do not correspond to what news text is trying to convey are rarely used.

\section{CONCLUSION}

This study identifies that there are three most frequent verb types; they are verbal, material, and existential in the corpus of news section of The Jakarta Post. Among several verbs in verbal type, verb say is the most frequent one. Verbal type occupies the most frequent position since the nature of news is to deliver information of factual events. In other words, news text reports what has happened or what is happening and thus it needs verbal verbs to convey the information. Alike verbal type, material verb is used quite often because it denotes concrete actions that are related to the events being reported and existential verb denotes the existence of the events. Both are definitely important in constructing news texts so that the text can fulfill its role. Besides the most frequent verb types, there are some less frequent ones including perception, feeling, cognition, possessive/relational, and relational types and the least ones are corporeal and perception/relational verb types. It is also evident that corporeal and perception/relational types are least frequent because corporeal deals with bodily gestures and perception/relational expresses the impression of things of which both are two unimportant, irrelevant concepts in news writing. To sum up, it is clear that frequency and text characteristics are strongly related; and that frequency is important to take into consideration in linguistic analysis, including in text analysis.

\section{REFERENCES}

Baker, P. (2010). Sociolinguistics and Corpus Linguistics. Edinburgh: Edinburgh University Press.

Bednarek, M., \& Caple, H. (2012). News Discourse. London: Continuum.

Bell, A. (1991). Language of News Media. Oxford: Blackwell.

Biber, D., \& Conrad, S. (2009). Register, Genre, and Style. Cambridge: Cambridge University Press.

Biber, D., \& Gray, B. (2016). Grammatical complexity in academic English: Linguistic change in writing. Cambridge: Cambridge University Press. 
Biber, D., \& Quirk, R. (Eds.). (2012). Longman grammar of spoken and written English (10. impression). Harlow: Longman.

Brezina, V., Timperley, M., \& McEnery, T. (2018). Lancsbox (Version 4.x.). Retrieved from http:/ / corpora.lancs.ac.uk/lancsbox.

Bybee, J. L., \& Hopper, P. J. (Eds.). (2001). Frequency and the emergence of linguistic structure. Amsterdam: Benjamins.

Chafe, W. L. (1970). Meaning and the Structure of Language. Chicago: University of Chicago Press.

Clackson, J. (2007). Indo-European Linguistics: An Introduction. Cambridge: Cambridge University Press.

Comrie, B. (2000). Tense. Cambridge [Cambridgeshire]; New York: Cambridge University Press.

Conboy, M. (2010). The language of newspapers: Socio-historical perspectives. London: Continuum.

Conrad, S., \& Biber, D. (Eds.). (2001). Variation in English: Multi-dimensional studies. Harlow, England; New York: Longman.

Davies, M. (2004). BYU-BNC. (Based on the British National Corpus from Oxford University Press. Retrieved from https://corpus.byu.edu/bnc/.

Davies, M. (2008). The Corpus of Contemporary American English (COCA): 560 million words, 1990-present. Retrieved from https://corpus.byu.edu/coca/.

Deng, F., \& Li, X. (2017). A Computer Corpus-based Study of FOREIGN in English Newspapers and its Pedagogical Implications. Eurasia Journal of Mathematics, Science and Technology Education, 13(10), 6799-6806. https:/ / doi.org/10.12973/ejmste/78278

Denyer, L. F. (2003). Corpus study carried out on three "legal" verbs to demonstrate their similar and different usage for the purposes of legal translators and lawyer-linguists. 20.

Dixon, R. M. W. (2005). A Semantic Approach to English Grammar. Oxford: Oxford University Press.

Halliday, M. A. K. (1990). Spoken and Written Language. Oxford: Oxford University Press.

Halliday, M. A. K., \& Matthiessen, C. M. I. M. (2004). An introduction to functional grammar (3rd ed). London: New York: Arnold; Distributed in the United States of America by Oxford University Press.

Leech, G. N., \& Short, M. (2007). Style in fiction: A linguistic introduction to English fictional prose (2nd ed). New York: Pearson Longman.

Leitner, G. (1986). Reporting the "events of the day": Uses and functions of reported speech. Studia Anglica Posnaniensia, 8, 189-204.

Moon, R. (2016). A Corpus-Linguistic Analysis of News Coverage in Kenya's Daily Nation and The Times of London. 21. 
Nordlund, M. (2008). From Physical to Mental Acquisition: A Corpus-Based Study of Verbs. Sweden: Lulea University of Technology.

Oktavianti, I. N. (2016). Quasi-modals in British and American English. Lingua Scientia, 8(2), 257-272.

Oktavianti, I. N. (2019). Verba Bantu Modal Bahasa Inggris: Karakteristik, Pemakaian, dan Perubahan. Gadjah Mada University, Yogyakarta.

Oxford Dictionary of English (Version 2014). Retrieved from https:/ / apps.apple.com/us/app/oxford-dictionary-ofenglish/id439106200? $\mathrm{mt}=12$

Stake, R. E. (2010). Qualitative research: Studying how things work. New York: Guilford Press.

Thomas, L., Wareing, S., Singh, I., Peccei, J. S., Thornborrow, J., \& Jones, J. (2004). Language, Society and Power: An Introduction, Second Edition. London: Routledge.

Wang, H. (2015). A Corpus-based Contrastive Study of Online News Reports on Economic Crisis - A Critical Discourse Analysis Perspective. Journal of Language Teaching and Research, 6(3), 627. https://doi.org/10.17507/jltr.0603.20

Yilmaz, M., \& Ertürk, Z. Ö. (2017). A Contrastive Corpus-based Analysis of the Use of Reporting Verbs by Native and Non-native ELT Researchers. Novitas-ROYAL (Research on Youth and Language), 11(2), 112-127.

Zarifi, V., \& Mukundan, J. (2013). Phrasal Verb Combinations in CorpusBased Studies: A Critical Review. International Journal of Applied Linguistics $\mathcal{E} \quad$ English Literature, 2(4), 212-217. https:/ / doi.org/10.7575/aiac.ijalel.v.2n.4p.212 